\title{
Improving Endurance of A Glider by using Solar Cells
}

\author{
Bassetti Chandrasheker \\ Cyient Ltd. (Hyderabad)
}

\author{
Mahesh K \\ Cyient Ltd. (Hyderabad)
}

\begin{abstract}
The main aim of this paper is to improve the endurance of a glider using solar cells. For this, a glider is initially modeled and analyzed which was later built and fabricated, a prototype of its kind. According to the area of a wing of the glider, a part of the wing is covered with the solar cells and tested to fly. To fulfill the aim of this paper, solar cells that would be appropriate with a good rating were chosen according to the electronic specifications used for a glider prototype. Also, the design of the glider ensured that the aerodynamic properties are efficient along with valid flight mechanic calculations.
\end{abstract}

\section{Keywords - Solar Glider; Buckboost converter; Solar Cells}

\section{INTRODUCTION}

Energy consumption is shifting from Non-Renewable energy resources such as fossil fuels to Renewable energy sources such as Sunlight for powering automobiles and aircraft. The sunlight falling on Earth in an hour has more energy than the people of the world use in a year. A SOLAR CELL is a little device that can make electricity right from sunlight. The dream of flight powered only by the sun's energy has long involved and motivated scientists. A solar aircraft is one that collects energy from the sun using photovoltaic solar cells. The energy may be used to drive an electric motor to power the aircraft. These airplanes store excess solar energy in batteries for night use. Small solar aircraft or drones can be used for transporting goods or materials between places at a short distance, provide internet access in remote areas and many more. Using solar panels there is more space due to the absence of engines and turbines. There have been quite a few manned and unmanned solar aircraft developed and flown.

On the 4th of November 1974, the first solar-powered aircraft flight took place on the dry lake at Camp Irwin, California. Sunrise I flew for 20 minutes at an altitude of around $100 \mathrm{~m}$. It weighed $12.25 \mathrm{~kg}$ and had a wingspan of $9.76 \mathrm{~m}$. The power output for the 4096 number of solar cells was $450 \mathrm{~W}$. An enhanced version, Sunrise II, was built and tested on the 12th of September 1975[1]. With the same wingspan, Sunrise II weight was reduced to $10.21 \mathrm{~kg}$ and the 4480 solar cells were able to deliver $600 \mathrm{~W}$. Thanks to their $14 \%$ efficiency. After dynamic testing, this second version got damaged due to a failure in the command and control system. Despite all complications, the history of solar flight was engaged and its first demonstration was through.

GOSSAMER PENGUIN was the world's first piloted solarpowered flight which was flown on 18th May 1980. It used the motors and solar panels of SUNRISE I AND II with a wingspan of $14.2 \mathrm{~m}$ and having 16128 solar cells offering $2500 \mathrm{~W}$. Solar Excel performed for about 11 hours 34 minutes in the air (overall) at an altitude of $2065 \mathrm{~m}$. It was flown in Germany in the year 1990 by Wolfgang Schaeper. Centurion was a high altitude long endurance plane that could stay airborne for weeks and serves as telecommunications relay platforms. It was able to carry $45 \mathrm{~kg}$ of remote sensing and a lithium battery was used to provide enough energy whenever required. The ultimate eternal airplane that incorporates energy storage for night time flight is the Helios. It was the last prototype of the HALE (High Altitude Long Endurance) series. NASA had two primary goals with this aircraft. First, the flight should reach an altitude of $30,480 \mathrm{~m}$ and the second was that it should fly for 24 hours nonstop [2]. Helios could reach the first objective but failed to fulfill the second one as it crashed down in the Pacific Ocean.

To prove the feasibility of the eternal flight of an unmanned airplane, SOLON was built in the year 2005. Using solar energy from the solar panels and the thermal energy coming from the sun, it flew for around 24 hours and 11 minutes with a wingspan of $4.75 \mathrm{~m}$. In December 2005 Zephyr achieved flight duration of 6 hours, reaching an altitude of $7925 \mathrm{~m}$. The longest flight duration was 54 hours in New Mexico on 10th September 2007 by Zephyr. The maximum altitude attained was 17786 meters. The wingspan of this aircraft is $18 \mathrm{~m}$ and weighs $30 \mathrm{~kg}$. The aircraft used solar panels during its ascent and uses the lithiumsulfur battery power as dusk fell [3]. Later, Solar Impulse was designed to overcome the limitations of the use of battery capacity. This aircraft used solar energy to power its four engines that produced a combined maximum power of $12 \mathrm{hp}$ and had a wingspan of 61 meters. This aircraft set a new world record by covering the entire globe using solar power.

\section{A. SOLAR CELLS AND THEIR EFFICIENCIES}

A device that converts the energy of light directly into electricity by the photovoltaic effect in solid-state is called a solar cell [4]. Solar panels term is used generally to describe them. The different types of solar cells mostly available are as shown [5]:

- Crystalline Silicon

- Monocrystalline

- Polycrystalline

- Thin-Film Solar Panels

\section{i. Crystalline Silicon (c-Si)}

Nearly $90 \%$ of the World's photovoltaics today are centered on some variation of silicon. The silicon used in PV takes many forms. The main change is the purity of the silicon. The more perfectly the silicon molecules are aligned, the better the solar cell will be at converting solar energy (sunlight) into electricity (the photoelectric effect). The efficiency of solar panels depends on purity, but the processes used to enhance the purity of silicon are expensive. Efficiency should not be your primary concern, cost-and space-efficiency are the determining factors for most people. Crystalline silicon forms the base of mono- and polycrystalline silicon solar cells. 


\section{ii. Monocrystalline Silicon Solar Cells}

Monocrystalline silicon (mono-Si) solar cells can be recognized easily by their external even coloring and look, indicating high-purity silicon. These solar cells are made out of cylindrical silicon ingots. To enhance performance and to make these cells cost-friendly, single monocrystalline solar cells, four sides are cut out of the cylindrical ingots to make silicon wafers, which gives monocrystalline solar panels their characteristic look.

\section{Advantages}

- They have peak efficiency rates since they are manufactured out of the highest-grade silicon. Monocrystalline solar panels have an efficiency rate typically between $15-20 \%$.

- These solar panels are space-efficient compared to any other type.

- Tend to perform better at low-light conditions when compared to similarly rated polycrystalline solar panels

\section{Disadvantages}

- They are the most expensive

- The entire circuit can break down if the solar panel is partially covered with shade, dirt or snow.

- They tend to be more efficient in warm weather.

\section{iii. Monocrystalline Silicon Solar Cells}

Polycrystalline silicon, which also is recognized as polysilicon (p-Si) and multi-crystalline silicon (mc-Si), was introduced in 1981. Unlike monocrystalline-based solar panels, polycrystalline solar panels do not require the Czochralski process, which is a method to manufacture semiconductor crystals. Instead, molten silicon is poured into a square mold, which is cooled and later cut into perfectly square wafers.

\section{Advantages}

- The manufacturing process is simple and cost-effective and the silicon wastage is less compared to monocrystalline.

- These solar panels comparatively have slightly lower heat tolerance than monocrystalline solar panels so they perform slightly worse than monocrystalline solar panels and at high temperatures, heat can effect the performance and shorten their lifespans. However, this effect is minimal need not be taken into account.

\section{Disadvantages}

- The efficiency is typically between $13-16 \%$.

- Lower space-efficiency. You generally need to cover a larger surface for fair output.

\section{iv. Thin - Film Solar Cells (TFSC)}

Thin-film solar cells, also known as thin-film photovoltaic cells (TFPV) are manufactured by depositing one or several thin layers of photovoltaic material onto a substrate. They are categorized based on which photovoltaic material is being deposited onto the substrate as shown below:

- Amorphous silicon (a-Si)

- Cadmium telluride (CdTe)

- Copper indium gallium selenide (CIS/CIGS)

- Organic photovoltaic cells (OPC)

Based on the technology, thin-film prototypes have attained efficiencies between $7-13 \%$ and production modules operate at about $9 \%$. Future module efficiencies are expected to reach about $10-16 \%$

\section{Advantages}

- Cheaper to manufacture than crystalline-based solar cells as they can be produced in mass and their homogenous appearance makes them look more appealing.

- It can be made flexible, which opens up many new potential applications.

- Less impact on performance at high temperatures and shading

- Thin-film solar panels can be used where space is not an issue.

\section{Disadvantages}

- Thin-film solar panels are cheap and are not very useful in most residential situations as they also require a lot of space.

- Low space-efficiency implies that the cost of PVequipment will increase.

- They degrade faster than monocrystalline and polycrystalline solar panels,

\section{B. BUCK-BOOST CONVERTER AND BALANCER}

This is an advanced battery arrangement used to charge the Li-ion batteries for a solar-powered aircraft. The total arrangement of Buck Boost Convertor and Balancer monitors and controls the storage and delivery of solar energy coming from the solar cells. For a solar-powered aircraft, the buckboost converter plays an important role to make the flight successful for a reasonable time. These are placed between the solar cells and the Li-ion battery [6]. The function of this convertor and balancer works like the Maximum Power Pointer Tracker, i.e. it helps in converting the solar power from the sun to the required input voltage and stored this energy using the balancer. This voltage acts like an input that can charge the batteries and gives a required constant output with the help of a balancer through which the aircraft can fly. As it is known that the cost of solar panels is high, the utilization of solar energy should be maximum [7]. To maintain the maximum utilization of solar energy, these buck-boost converters are used. They are efficient, accurate and light-weight to use. The buck-boost converter is used to convert the high and low voltages to a load terminal voltage without changing the voltage polarity. The figure shows a diagram of the buck boost converter circuit. Metal-Oxide-Semiconductor-Field-Effect-Transistors (MOSFETs) are used in the circuits to controls the flow of energy to load terminals [7].

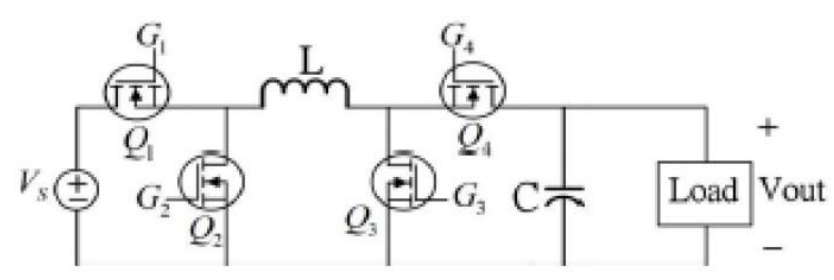

Fig 1. Synchronous Buck-Boost Converter

Through proper control of the power MOSFETS, the power converters operate in three modes, buck, buck-boost and boost 
mode. There is variation in the modes due to the variation in the power supply.

- When the supply voltage is higher than the load voltage, the convertor is set back to the buck mode.

- When the supply voltage is less than load voltage, the convertor is set back to the boost mode.

- When the supply voltage is closed to the load voltage, the convertor is set back to the buck-boost mode.

The circuit consists of an inductor (L), and four transistors $\left(\mathrm{Q}_{1}, \mathrm{Q}_{2}, \mathrm{Q}_{3}\right.$ and $\left.\mathrm{Q}_{4}\right)$. The three modes depend on controlling the power switches of the transistors and energy storage in the inductor [8]. In the buck mode operation, transistors $\mathrm{Q}_{1}$ and $\mathrm{Q}_{2}$ are controlled. For charging the inductor, transistor $\mathrm{Q}_{1}$ is closed and $\mathrm{Q}_{2}$ is open. This makes the current increase in the inductor almost linearly and the capacitor supplies the output current to the load. For discharging the inductor, transistor $\mathrm{Q}_{2}$ is closed and $\mathrm{Q}_{1}$ is open. Inductor current decreases linearly. For the buck operation, if the duty cycle for charging the inductor is $\mathrm{d}$, the average load voltage $V_{\text {out }}$ equals $d_{\mathrm{s}}$. Duty cycle $\mathrm{d}<1, \mathrm{~V}_{\text {out }}<$ $\mathrm{V}_{\mathrm{s}}$. In the boost mode operation, transistor $\mathrm{Q}_{1}$ is on and $\mathrm{Q}_{2}$ is off. During charging, transistor $\mathrm{Q}_{3}$ is closed and $\mathrm{Q}_{4}$ is open. For discharging, transistor $\mathrm{Q}_{3}$ is open and $\mathrm{Q}_{4}$ is closed. In this mode, the average voltage $\mathrm{V}_{\text {out }}$ equals to $1 /(1-\mathrm{d}) \mathrm{Vs}$. Therefore, the output voltage can be higher than the input supply voltage.

In the buck-boost mode operation, transistor $\mathrm{Q}_{1}$ andQ 3 work as a group and $\mathrm{Q}_{2}$ and $\mathrm{Q}_{4}$ works as a group. To charge the inductor, switch $\mathrm{Q}_{1}$ and $\mathrm{Q}_{3}$ are kept close and $\mathrm{Q}_{2}$ and $\mathrm{Q}_{2}$ are kept open. To discharge the inductor, the inverse is done. The average voltage $V_{\text {out }}$ is equal to $d /(1-d) V_{s}$. This implies that the output voltage can be changed to more or less the input supply voltage [9].

\section{DESIGNING A GLIDER}

Designing a Glider was done bearing in mind two main objectives:
a. Modeling a glider
b. Analyzing the glider model

\section{A. Modeling a glider}

The Modeling and assembly of the glider was done using CATIA software and its different sketches and images are as shown below.

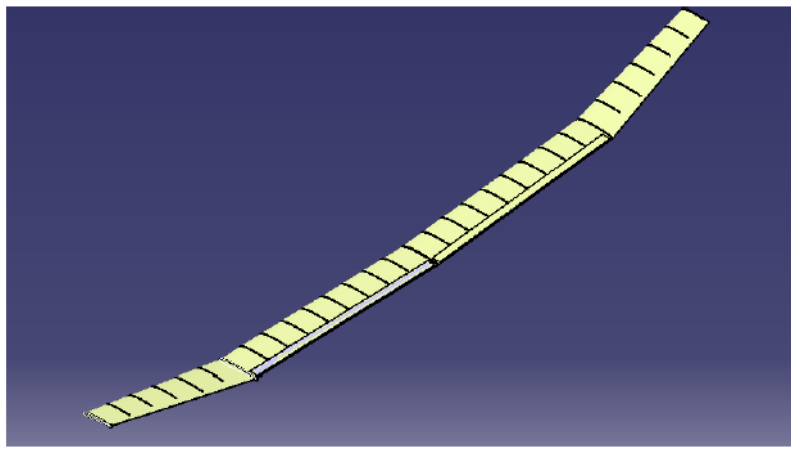

Fig 2. Isometric view of wing having a length $2000 \mathrm{~mm}$

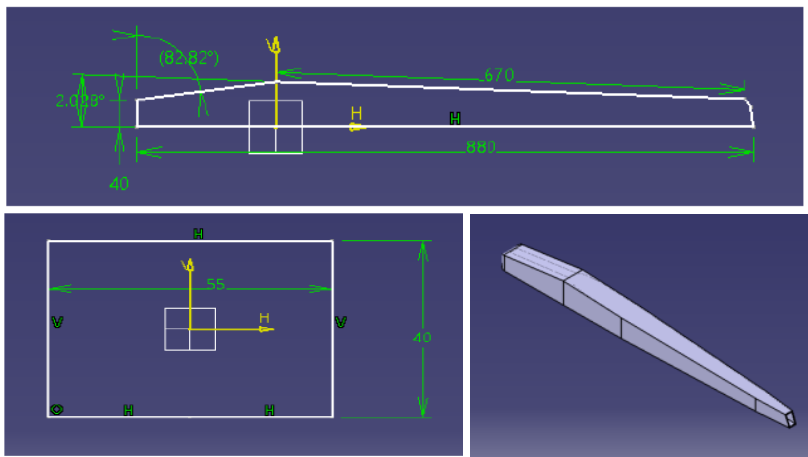

Fig 3. Fuselage with its dimensions

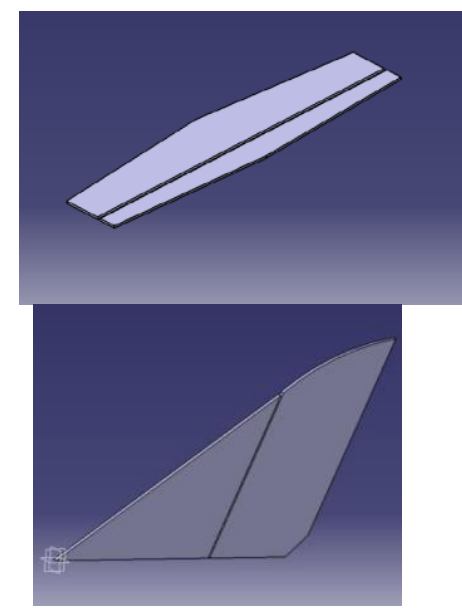

Fig 4. Horizontal and Vertical Stabilizer

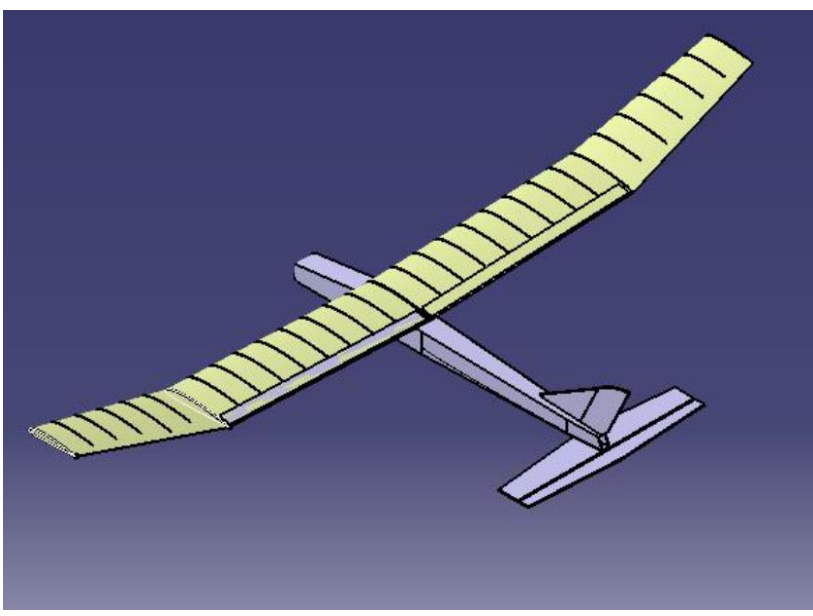

Fig 5. Isometric view of the final assembly of the glider

\section{B. Analyzing the glider model}

The analysis of the glider was done in ANSYS Workbench 14.0 and its boundary conditions given are as shown below:

- Inlet velocity $=15 \mathrm{~m} / \mathrm{s}$

- $\quad$ Pressure $=101325 \mathrm{~Pa}$

- Density $=1.2256 \mathrm{~kg} / \mathrm{m}^{3}$

- $\quad$ Energy equation $=$ Off

- Angle of Attack = 10 degree

Once the above inputs are given, the resulting graphs for Coefficient of Lift $\left(\mathrm{C}_{\mathrm{L}}\right)$ and Coefficient of drag $\left(\mathrm{C}_{\mathrm{D}}\right)$ observed are as shown below: 


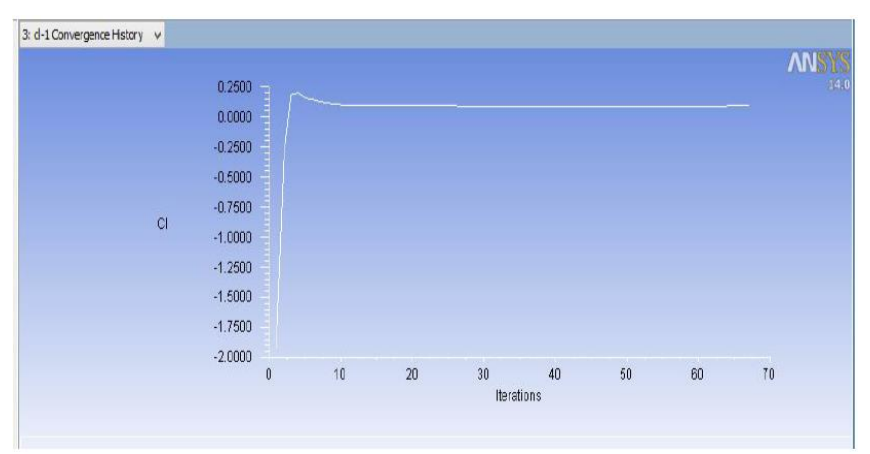

Graph 1. $\mathrm{C}_{\mathrm{L}}$ vs Iterations curve

From the above graph, we observe that the values of $\mathrm{C}_{\mathrm{L}}$ initially increases, became constant and gets converged at 67 th iteration with a value of 0.15 and observed $\mathrm{C}_{\mathrm{L} \text { max }}$ is 0.24

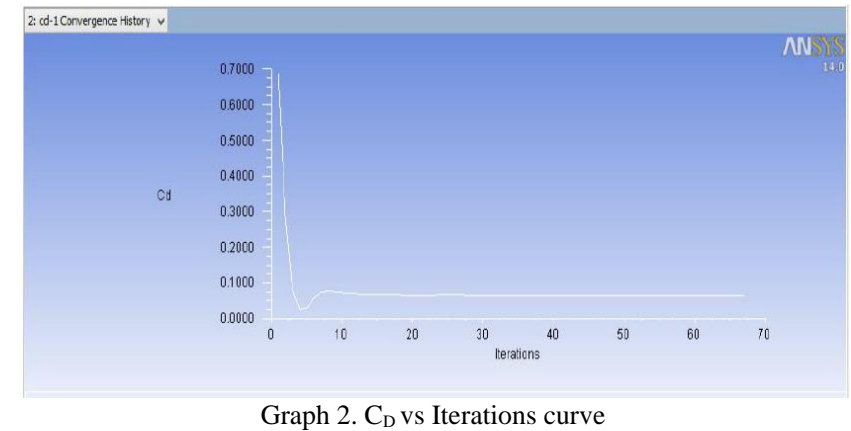

From the above graph, we observe that the values of $C_{D}$ initially decrease and then increase slightly followed by a constant value of 0.075 which is obtained at 67 th iteration.

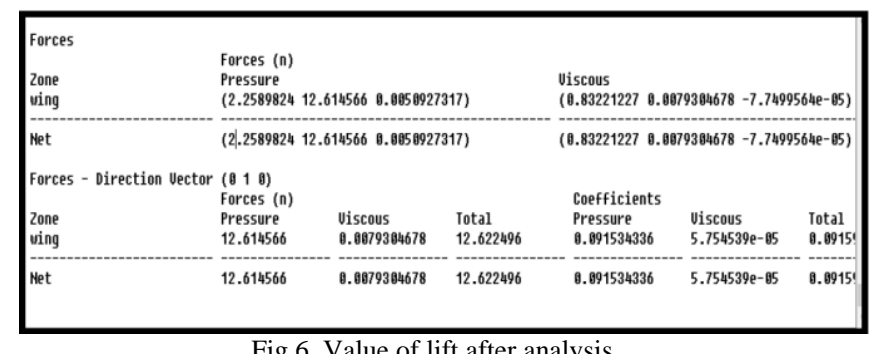

Fig 6. Value of lift after analysis

The results for lift after the analysis are obtained as shown in the above figure and the lift generated is approximately equal to 12.6 Newton.

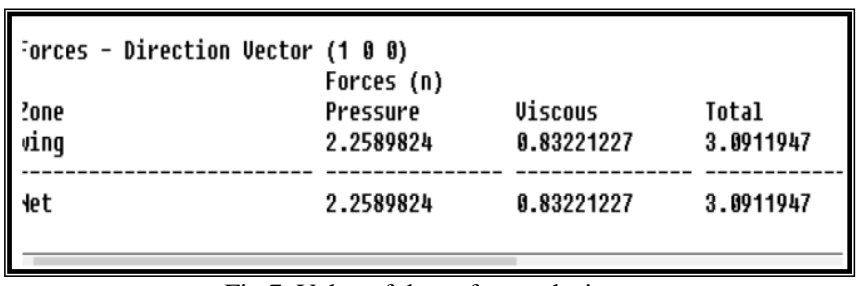

Fig 7. Value of drag after analysis

Similarly, the value of drag after analysis as shown in the above figure is approximately equal to 2.26 Newton.

\section{Comparison of theoretical vs analytical results}

After modeling in CAD and analyzing in Fluent, a live prototype of the glider was built to which suitable solar cells were connected on wings and then tested. Study and calculation of different parameters i.e., lift force, drag force, thrust, weight, gravity, etc. using appropriate formulas to design solar aircraft was done [10]. Later, different tests like lift test, drive test, flight test, etc. was done. This is purely analytical and based on the concepts of energy and mass balances that put the sizing of all elements on the airplane in relation. The various parameters of the glider prototype are as shown below:

1. Wing Span (b) $=202 \mathrm{~cm}$

2. Chord Length (c)

At the tip, $c_{t}=5 \mathrm{~cm}$

At the root, $c_{r}=17.5 \mathrm{~cm}$

Mean chord, $\mathrm{c}_{\text {mean }}=11.25 \mathrm{~cm}$

3. Aspect Ratio $(b / c)=11.54$

4. Plan-form Area of the wing $(S)=3535 \mathrm{~cm}^{2}$

5. Thickness $(\mathrm{t})=2.1 \mathrm{~cm}$

6. Fineness Ratio $\left(C_{\text {mean }} / t\right)=5.36$

7. Empty Weight of Glider $\left(\mathrm{W}_{\text {empty }}\right)=350$ grams (approx.)

8. Payload $\left(\mathrm{W}_{\text {payload }}\right)=250$ grams (approx.)

9. Total Weight $=\mathrm{W}_{\text {empty }}+\mathrm{W}_{\text {payload }}=600$ grams

10. Wing Loading $(W / S)=0.99 \mathrm{~kg} / \mathrm{m}^{2}$

11. Thrust $(\mathrm{T})=1 \mathrm{~kg}=9.8$ Newton

Using the values of Lift and Drag form analysis results to calculate:

12. Coefficient of Lift $\left(\mathrm{C}_{\mathrm{L}}\right)=\frac{L}{\frac{\rho v_{\infty}^{2} S}{2}}=0.15$
13. Coefficient of Drag $\left(\mathrm{C}_{\mathrm{D}}\right)=\frac{{ }_{D}}{\frac{\rho v_{\infty}^{2} S}{2}}=0.075$

Comparing theoretical results and analytical results we get:

14. Lift

$\mathrm{L}_{\mathrm{th}}=11.56$ Newton

$\mathrm{L}_{\text {anly }}=12.61$ Newton

$\%$ error $=0.08 \%$

15. Drag

$\mathrm{D}_{\mathrm{th}}=3.61$ Newton

$\mathrm{D}_{\text {anly }}=2.26$ Newton

$\%$ error $=0.37 \%$

\section{TESTING THE GLIDER USING SOLAR CELLS}

After fabricating the glider, it was mounted using 26 polycrystalline solar cells due to unavailability of thin-film solar cells and many other factors like:

- The Efficiency of poly-crystalline solar cells is about 13$15 \%$.

- Easily available in India.

- Next most cost-efficient after thin film solar cells.

- They perform well at moderate weather conditions. 
The glider was initially ground tested to check for the increase in endurance. The objective was to test the solar airplane during solar-powered long duration flight. Due to the state of technology, especially concerning batteries, this goal is best possible with very good weather conditions. The test flight was done at mid-noon with a full battery, charged by the sun. The airplane battery acted as a source of power for 14 minutes \& 04 seconds before completely getting discharged. Later the test was done again while keeping solar cells along with battery as a source of power to check for the increased time of flight.

For Solar Cells, Lithium-ion batteries are used which consists of 3 cells. Each cell has a voltage of 3.7V. Hence, the voltage of the battery is $11.1 \mathrm{~V}$ with a minimum output voltage of $3 \mathrm{~V}$ and a maximum voltage of $4.2 \mathrm{~V}$ for each battery [11].

$$
\begin{aligned}
& \text { A. Input } \\
& \begin{aligned}
\mathrm{V}_{\text {(solar min) }} & =\mathrm{n}_{\text {(cell) }} \times \mathrm{V}_{\text {(cell min) }} \\
& =26 \times 0.4 \\
& =10.4 \mathrm{~V} \\
\mathrm{~V}_{(\text {solar max })} & =\mathrm{n}_{\text {(cell) }} \times \mathrm{V}_{\text {(cell max })} \\
& =26 \times 0.6 \\
& =15.6 \mathrm{~V}
\end{aligned}
\end{aligned}
$$

Where $\mathrm{n}_{\text {(cell) }}$ is the number of solar cells used

\section{B. Output}

$$
\begin{aligned}
\mathrm{V}_{\text {(batt min) }} & =\mathrm{n}_{(\text {LIPO) }} \times \mathrm{V}_{\text {(LIPO min) }} \\
& =3 \times 3 \\
& =9 \mathrm{~V} \\
\mathrm{~V}_{\text {(batt max })} & =\mathrm{n}_{\text {(LIPO) }} \times \mathrm{V}_{\text {(LIPO max })} \\
& =3 \times 4.2 \\
& =12.6 \mathrm{~V}
\end{aligned}
$$

Where $\mathrm{n}_{\text {(LIPO) }}$ is the number of cells in the LIPO battery.

\section{Maximum Charge Current}

$$
\begin{aligned}
\text { Maximum power } \mathrm{P}_{(\text {solar max })} & =\mathrm{n}_{(\text {cell })} \times \mathrm{P}_{(\text {cell max })} \\
& =26 \times 1 \mathrm{~W} \\
& =26 \mathrm{~W}
\end{aligned}
$$

Here, $\mathrm{P}_{\text {(cell } \max )}$ is the power rating of the solar cell.

Maximum charge current

$$
\begin{aligned}
\mathrm{I}_{(\text {charge } \max )} & =\mathrm{P}_{(\max ) /} \mathrm{V}_{(\text {batt min })} \\
& =28 / 9 \\
& =2.9 \mathrm{amp}
\end{aligned}
$$

The battery is rated for a charge rate up to 5 amps, so this is within its capabilities

\section{Theoretical Calculations For Voltage}

Theoretical calculations according to the rating are

Voltage of 1 solar cell $=5 \mathrm{~V}$

Voltage of 26 solar cells

$$
\begin{aligned}
\frac{1}{v_{\text {total }}} & =\frac{1}{v_{1}}+\frac{1}{v_{2}}+\frac{1}{v_{3}}+\ldots \ldots \ldots \ldots \ldots \cdot \frac{1}{v_{26}} \\
\frac{1}{v_{\text {total }}} & =\frac{26}{5}=5.2 \\
\mathrm{~V}_{\text {total }} & =0.192 \mathrm{~V}
\end{aligned}
$$

\section{E. Experimental Calculations For Voltage}

Voltage of 1 solar cell $=3.5 \mathrm{~V}$

Voltage of 26 solar cells

$$
\begin{aligned}
\frac{1}{v_{\text {total }}} & =\frac{1}{v_{1}}+\frac{1}{v_{2}}+\frac{1}{v_{3}}+\ldots \ldots \ldots \ldots \ldots \frac{1}{v_{26}} \\
\frac{1}{v_{\text {total }}} & =\frac{26}{3.5}=7.42 \\
\mathrm{~V}_{\text {total }} & =0.134 \mathrm{~V}
\end{aligned}
$$

After connecting the buck boost converter the voltage has stabilized to $0.2 \mathrm{~V}$ which is an additional input for the batteries.

The test flight was done again using a mounted solar cell model and the time of flight increased to 14 minutes \& 58 seconds. Hence the objective was accomplished. Currently, flying continuously with solar energy is still a big challenge that requires special conditions and that is possible only during a short interval in summer. But in the future, improvements in battery, solar cells and composite technologies will make the task easier, over a larger period and make such systems be used for a wide range of applications

\section{CONCLUSION}

The study presented a new methodology for the conceptual design of solar aircraft. It has the advantage to be versatile and usable for large aircraft. Wing having NACA 2412 profile is selected over CLARK Y because it has a good characteristic of lift and is easy to design. This profile was accurate for model size. The solar cell best suited is also selected i.e polycrystalline. The main objective was to increase the endurance by using solar energy which was accomplished as the time of flight increased from 14 minutes \& 04 seconds to 14 minutes $\& 58$ seconds. This result may have been varied if more efficient solar cells were used. Among the common needs, solar-powered aircraft have the applications like weather forecasting, communication platforms for electronic handsets, environmental monitoring and surveillance for military purposes, providing Free Wi-Fi zone for some areas for a certain time period and network jammers can also be installed who's power source depends on solar cells.

\section{REFERENCES}

[1] Noth, A., 2008. Design of solar powered airplanes for continous flight (Doctoral dissertation, ETH Zurich).

[2] NASA, Solar Powered Fact Sheet. "Solar-Power Research and Dryden" URL: http://www.dfrc.nasa.gov/PAO/PAIS/HTML/FS-054-DFRC.htm

[3] Solar-facts-and-advice.com. (2013). Solar Energy Facts and Advice. [online] Available at: http://www.solar-facts-and-advice.com/ [Accessed 16 Jan. 2019].

[4] Solarlove.org. (2013). Which Solar Panels Are Most Efficient? [online] Available at: http://solarlove.org/which-solar-panels-mostefficient/ [Accessed 04 Oct. 2018]

[5] Kebede, R. (2014). Australia develops world's most efficient solar panels. [online] RT International. Available at: http://rt.com/business/212383-australia-record-solar-energy/ [Accessed 0 Oct. 2018].

[6] Enslin, J.H.R., 1990, November. Maximum power point tracking: a cost saving necessity in solar energy systems. In [Proceedings] IECON'90: 16th Annual Conference of IEEE Industrial Electronics Society (pp. 1073-1077). IEEE.

[7] Weissbach, R.S. and Torres, K.M., 2001, April. A noninverting buck boost converter with reduced components using a microcontroller. In 
Proceedings. IEEE SoutheastCon 2001 (Cat. No. 01CH37208) (pp. 7984). IEEE.

[8] Shiau, J.K. and Ma, C.W., 2013. Li-ion battery charging with a buckboost power converter for a solar powered battery management system. Energies, 6(3), pp.1669-1699

[9] Marangoni, G., 2010. Battery management system for li-ion batteries in hybrid electric vehicles

[10] Niu, C., 1988. Airframe structural design: practical design information and data on aircraft structures. Conmilit Press.

[11] Villalva, M.G., Gazoli, J.R. and Ruppert Filho, E., 2009. Comprehensive approach to modeling and simulation of photovoltaic arrays. IEEE Transactions on power electronics, 24(5), pp.1198-1208 